Supporting Information For

\title{
A Mitochondria-Targeting and Reversible Near-Infrared Emissive Iridium(III) Probe for in vivo ONOO-/GSH Redox Cycles Monitoring
}

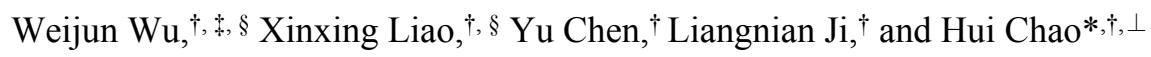

$\dagger$ MOE Key Laboratory of Bioinorganic and Synthetic Chemistry, School of Chemistry, Sun Yat-Sen University, Guangzhou 510275, P. R. China.

E-mail: ceschh@mail.sysu.edu.cn; Fax: +86-20-84112245; Tel: +86-20-84110613

$\$$ Department of Biomedical Engineering, Southern University of Science and Technology, Shenzhen 518055, P. R. China.

$\perp$ MOE Key Laboratory of Theoretical Organic Chemistry and Functional Molecule, School of Chemistry and Chemical Engineering, Hunan University of Science and Technology,

Xiangtan, 400201, P. R. China. 


\section{Contents}

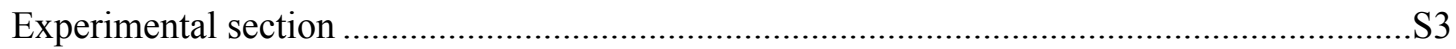

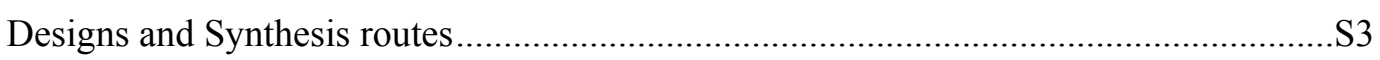

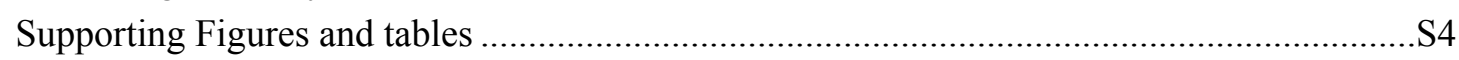

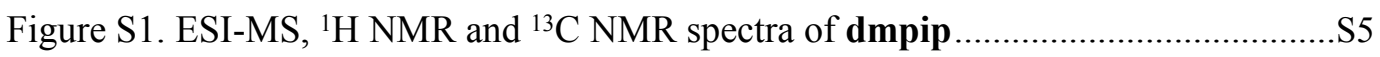

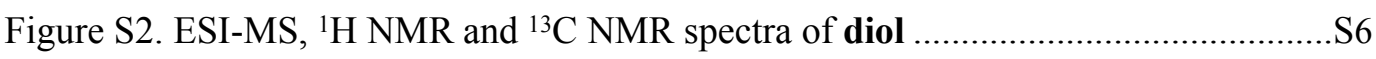

Figure S3. ESI-MS, ${ }^{1} \mathrm{H}$ NMR and ${ }^{13} \mathrm{C}$ NMR spectra of complex Ir-diol .........................S8

Figure S4. ESI-MS spectra of the product of the reaction of Ir-diol with $\mathrm{ONOO}^{-}$...........S9

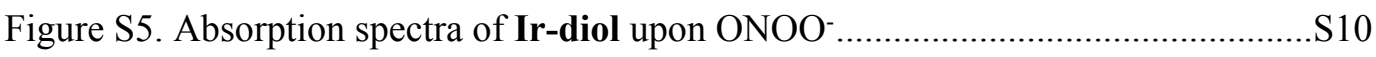

Figure S6. Phosphorescence and linear response of Ir-diol toward $\mathrm{ONOO}^{-}$...................S10

Figure S7. Phosphorescence and linear response of Ir-diol-ONOO- toward GSH ........S11

Figure S8. Phosphorescence response of Ir-diol to ONOO-/GSH redox cycles .............S11

Figure S9. MTT assay data of cells incubated for $12 \mathrm{~h}$ with $0-20 \mu \mathrm{M}$ Ir-diol ................S12

Figure S10. MTT assay data of cells incubated for $24 \mathrm{~h}$ with 0-20 $\mu \mathrm{M}$ Ir-diol .............S12

Figure S11. MTT assay data of cells incubated for various time with $5 \mu \mathrm{M} \mathbf{~ I r - d i o l ~ . . . . . S 1 2 ~}$

Figure S12. The co-localization confocal imaging of Ir-diol with comercial dyes .......S13

Figure S13. ICP-MS assay data in HepG2 and RAW264.7 cells ..................................S13 


\section{Experimental section}

\section{Designs and Synthesis routes}

\section{Synthesis}

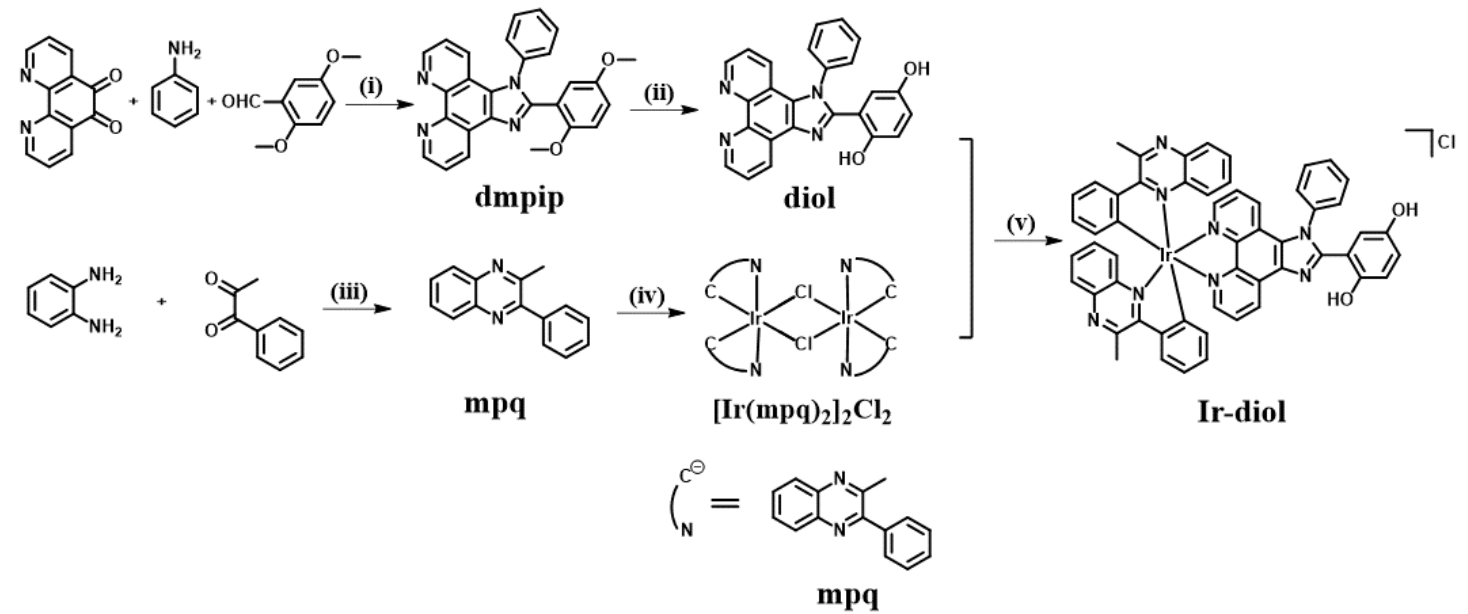

Scheme S1. Synthetic process of Ligand and Ir-diol. (i) $\mathrm{NH}_{4} \mathrm{OAc}, \mathrm{CH}_{3} \mathrm{COOH}$, reflux overnight. (ii) $\mathrm{BBr}_{3}, \mathrm{CH}_{2} \mathrm{Cl}_{2}$, Argon atomosphere. (iii) $\mathrm{CH}_{3} \mathrm{CH}_{2} \mathrm{OH}$, reflux. (iv) $\mathrm{IrCl}_{3}, \mathrm{H}_{2} \mathrm{O} / 2$-methoxyethanol, Argon atomosphere, reflux, dark, $24 \mathrm{~h}$. (v) $\mathrm{CHCl}_{3} / \mathrm{CH}_{3} \mathrm{OH}$, Argon atomosphere, reflux, dark, $12 \mathrm{~h}$. 


\section{Supporting Figures and tables}
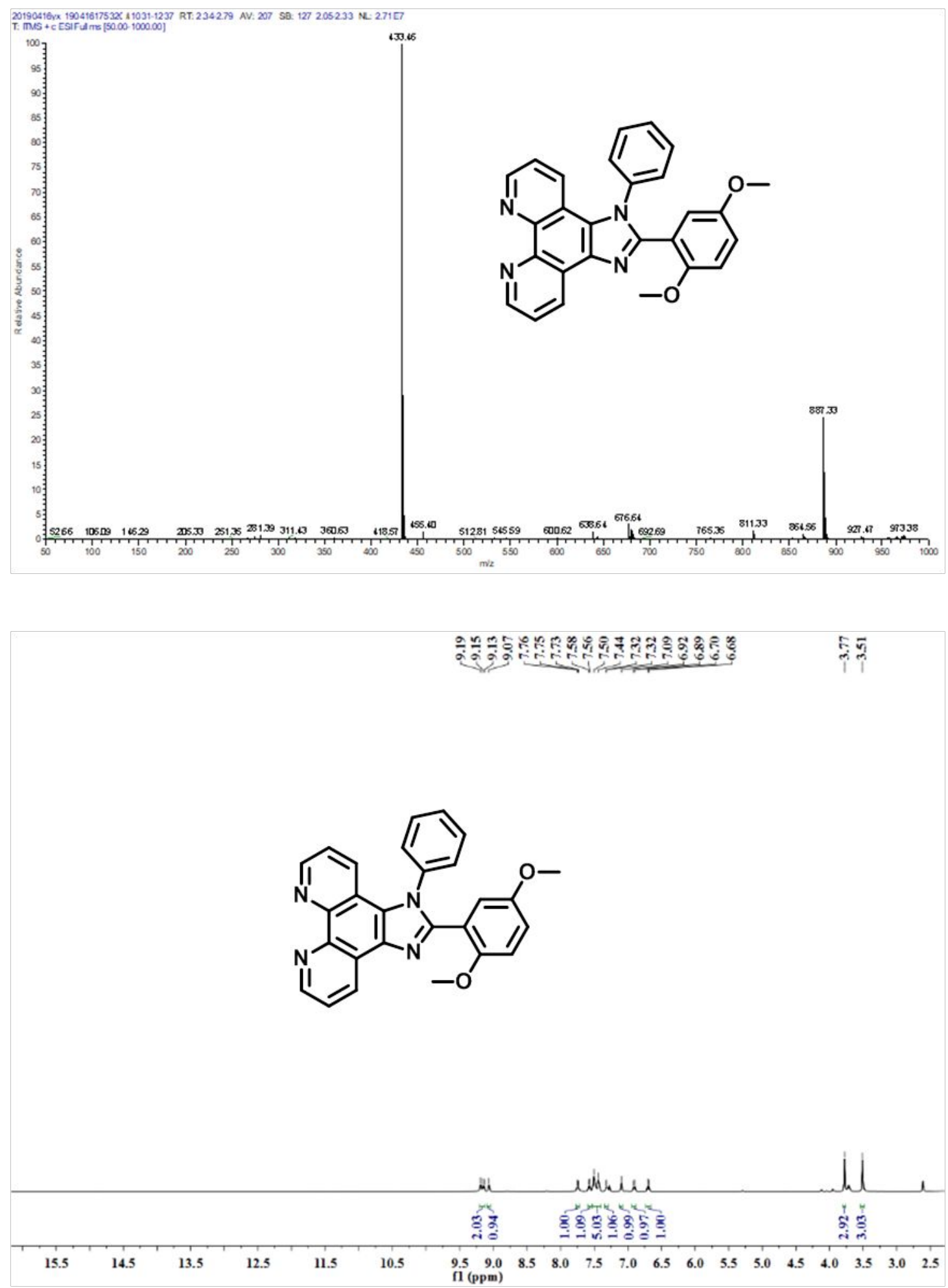
Figure S1. ESI-MS, ${ }^{1} \mathrm{H}$ NMR and ${ }^{13} \mathrm{C}$ NMR spectra of dmpip.

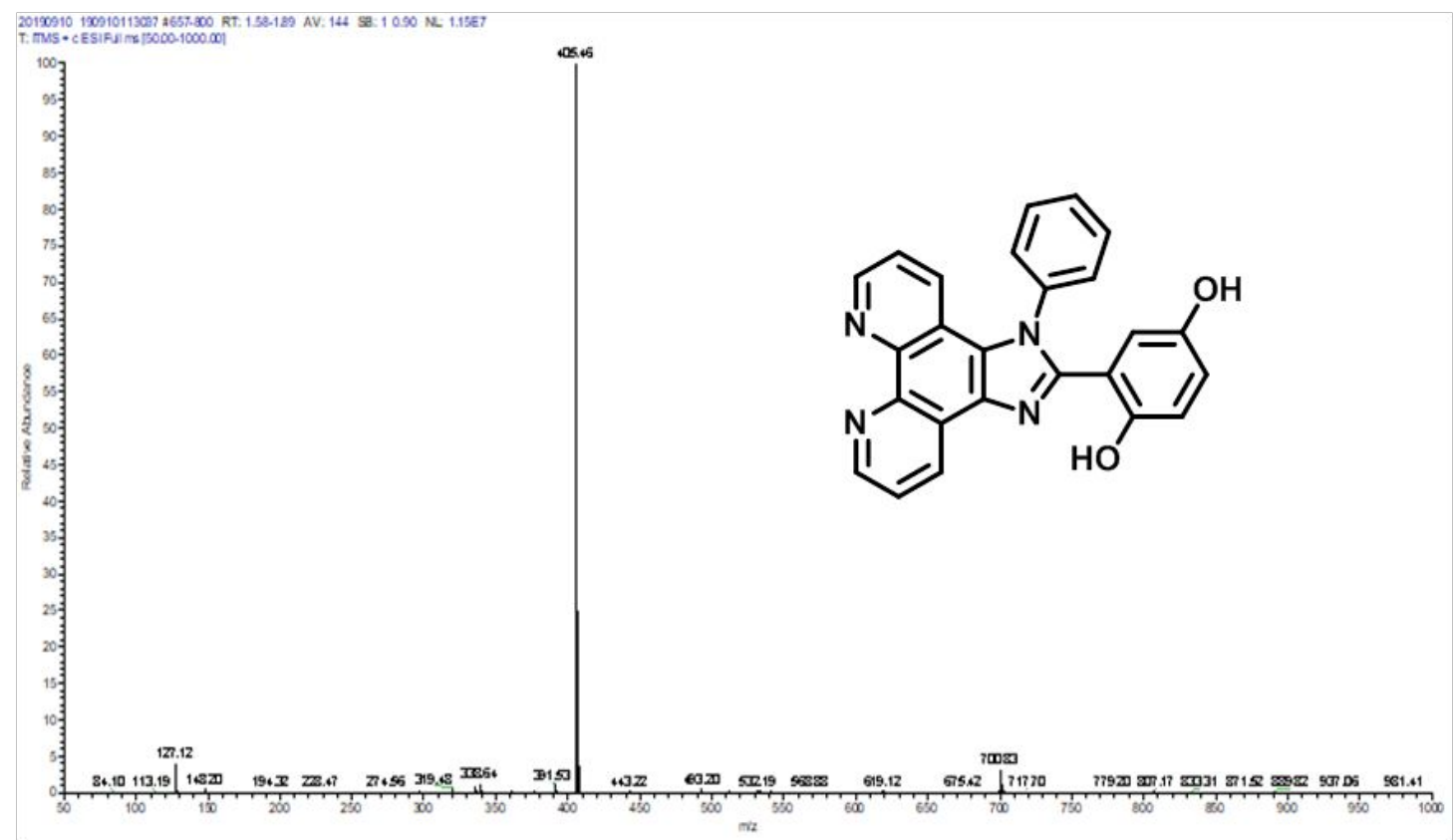



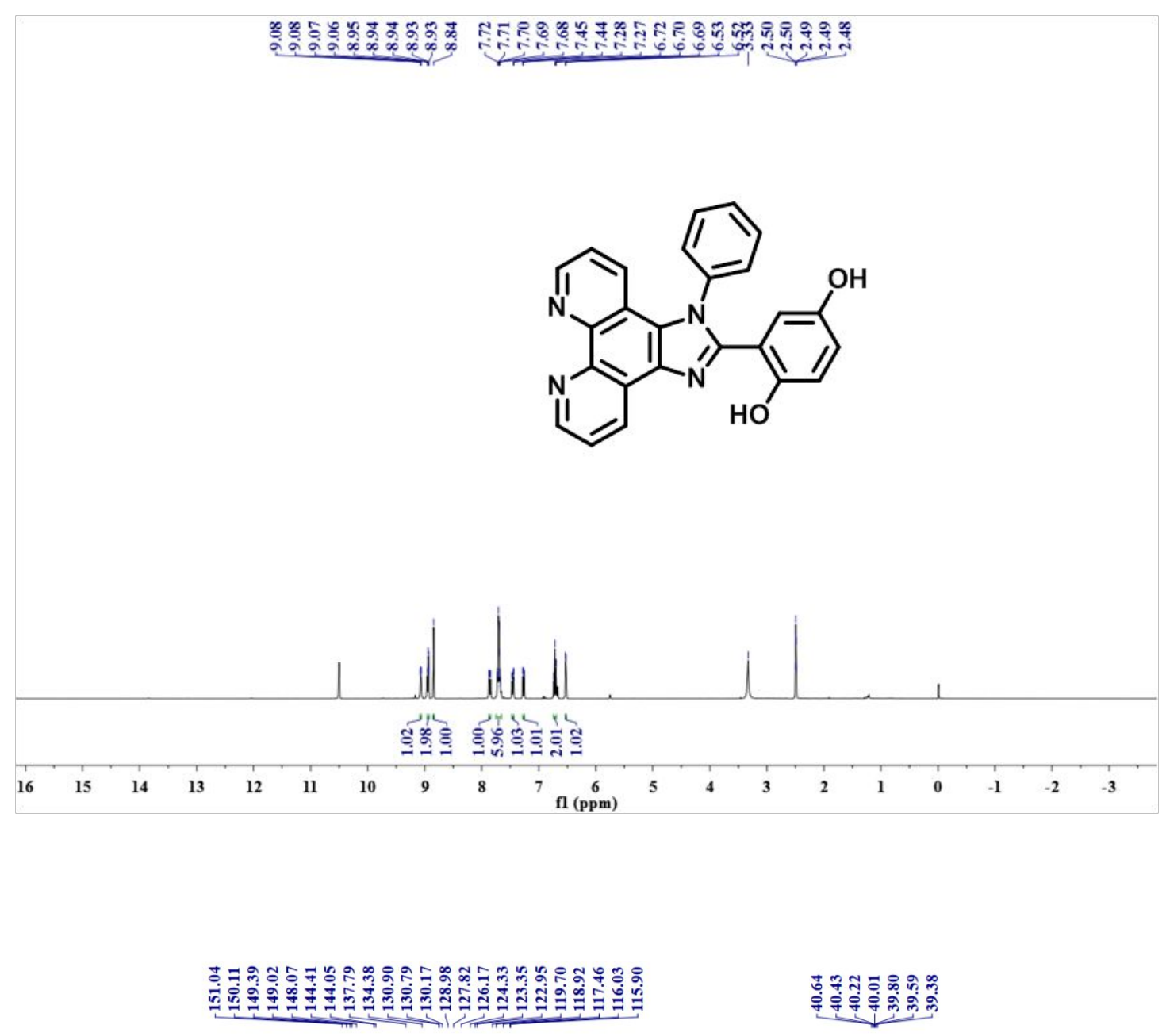

Figure S2. ESI-MS, ${ }^{1} \mathrm{H}$ NMR and ${ }^{13} \mathrm{C}$ NMR spectra of diol. 


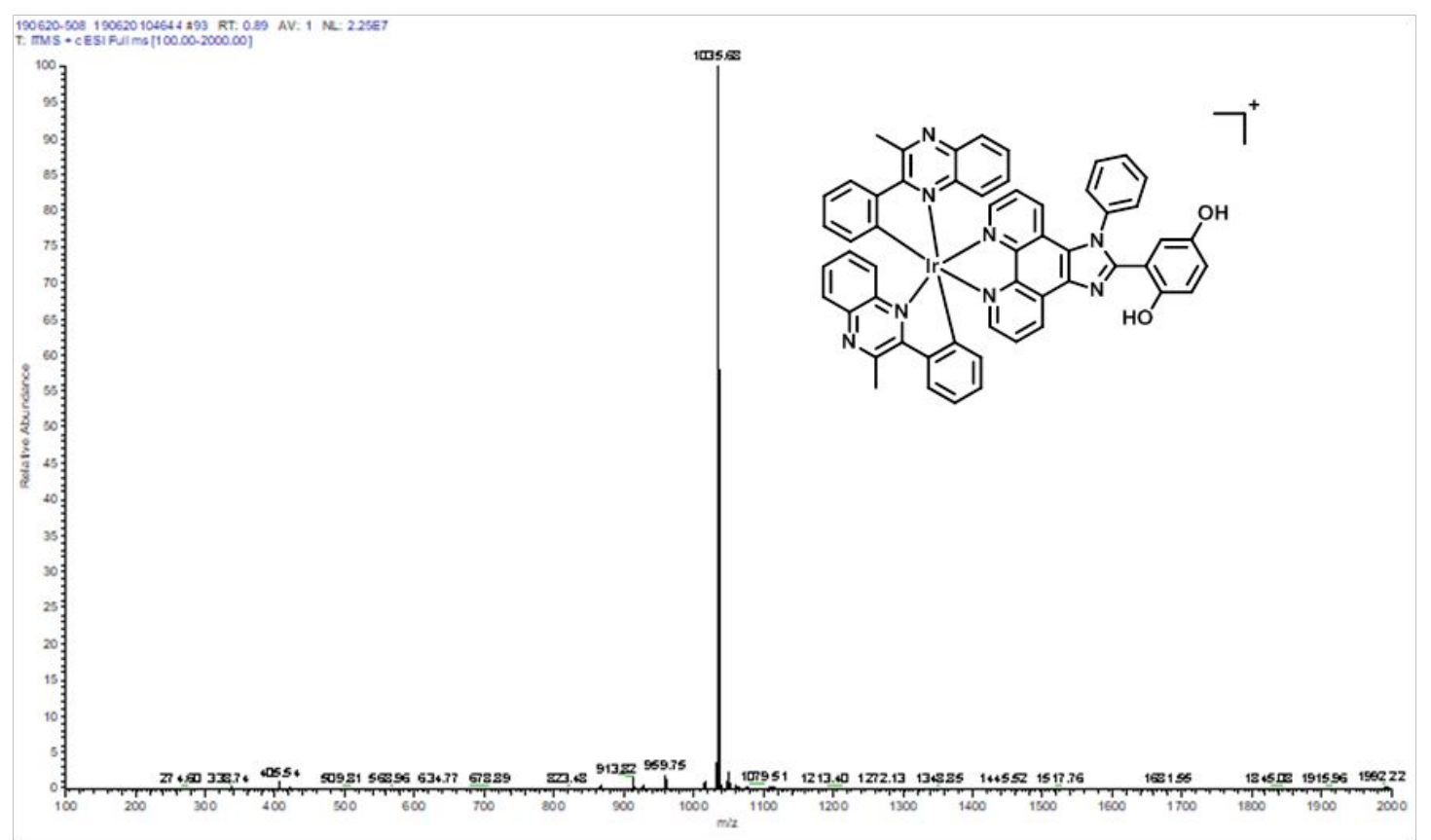

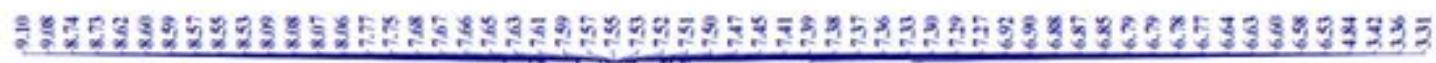

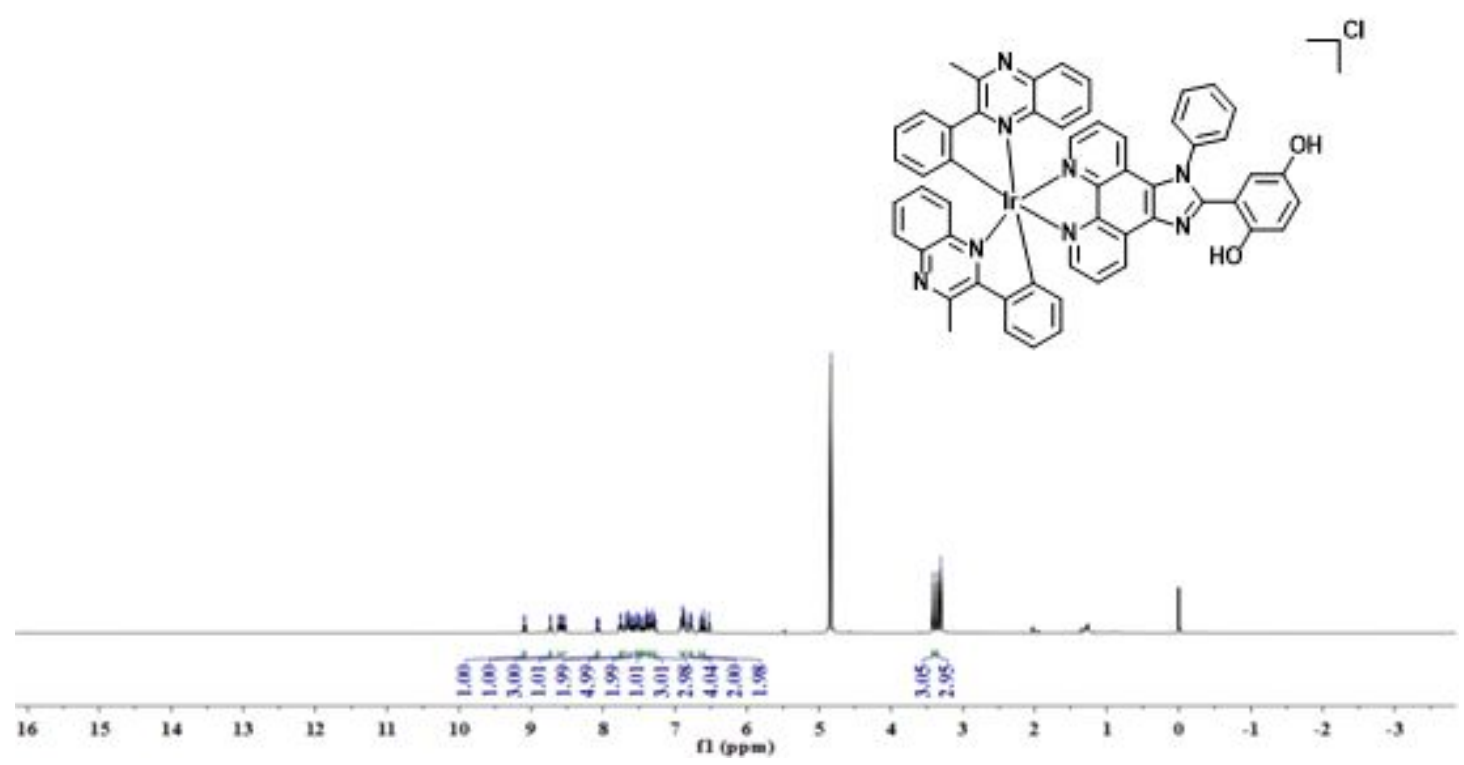




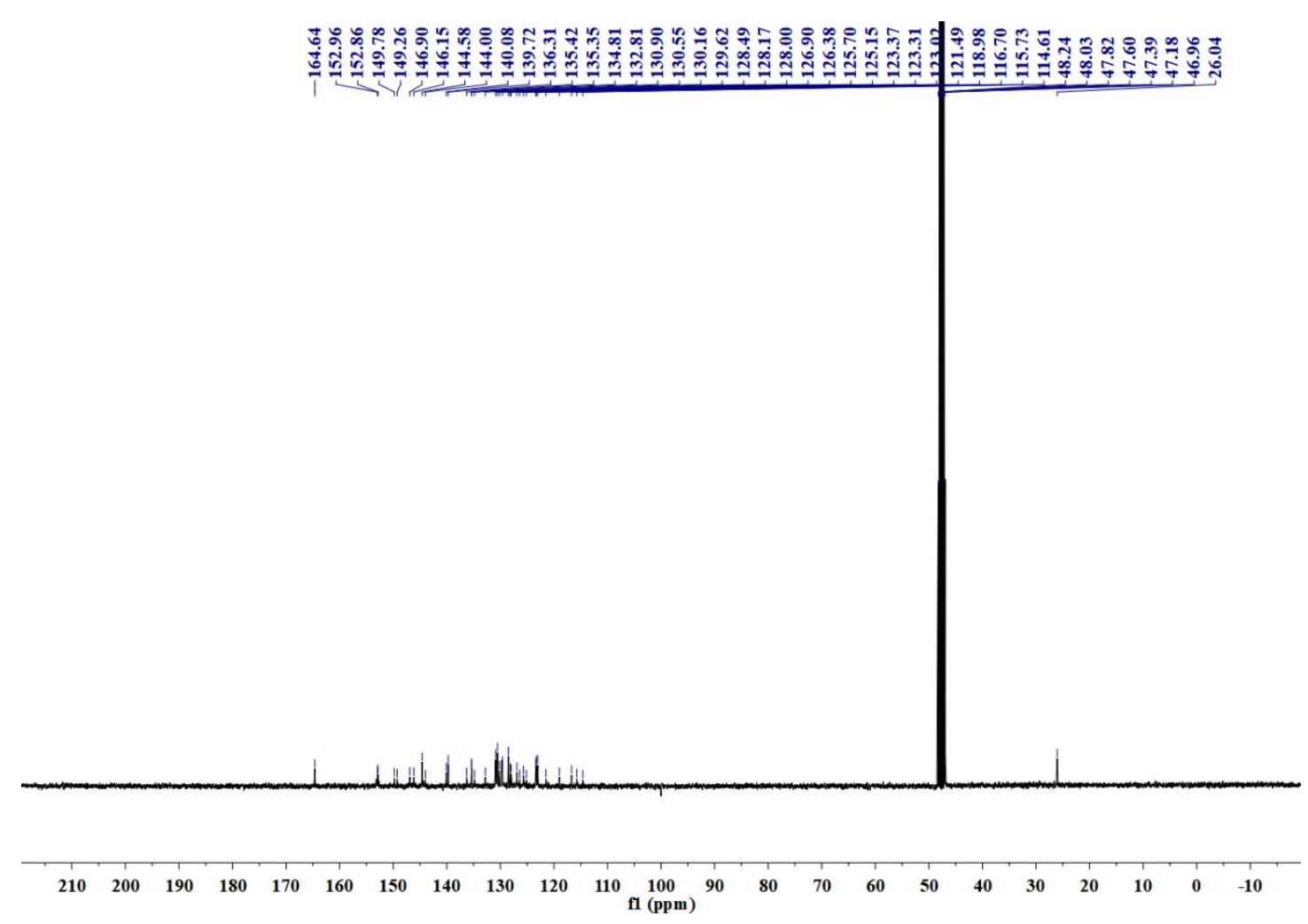

Figure S3. ESI-MS, ${ }^{1} \mathrm{H}$ NMR and ${ }^{13} \mathrm{CNMR}$ spectra of complex Ir-diol. 

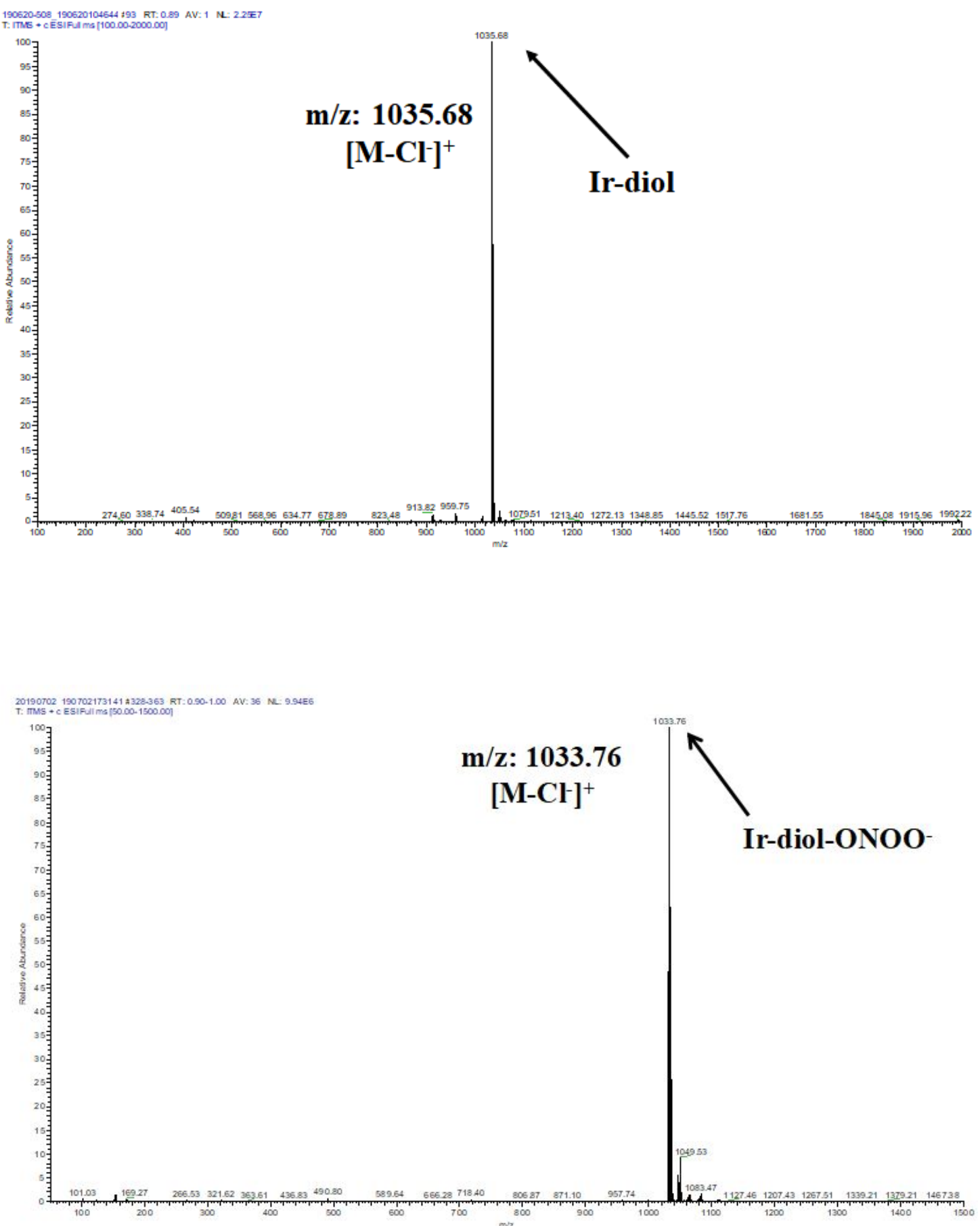

Figure S4. Mass spectra of the product by the reaction of Ir-diol with ONOO- in PBS buffer (containing 10\% DMSO) at $\mathrm{pH} 7.4$. 


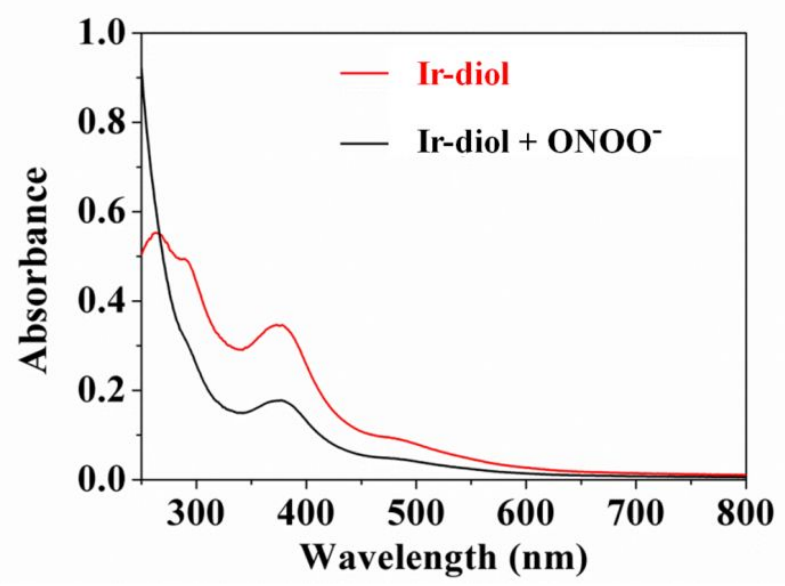

Figure S5. The absorption spectra of $5 \mu \mathrm{M}$ Ir-diol upon excess ONOO- in PBS buffer $(\mathrm{pH}=7.4$, containing $10 \%$ DMSO).

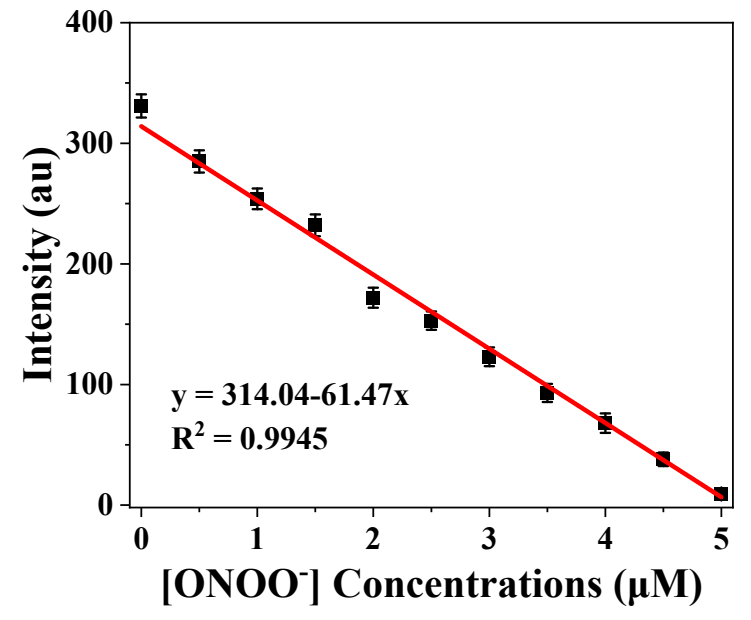

Figure S6. The change in the phosphorescence and linear response of Ir-diol $(5 \mu \mathrm{M})$ toward different concentrations of $\mathrm{ONOO}^{-}$. 


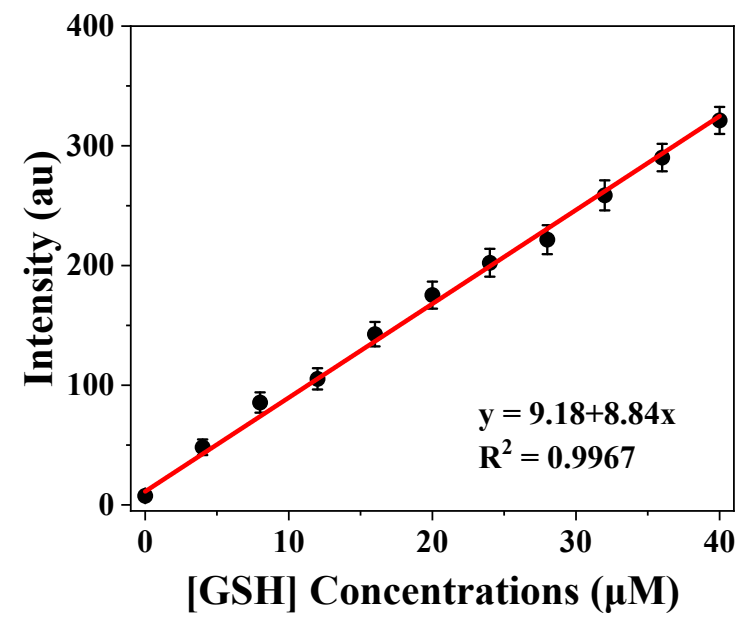

Figure S7. The change in the phosphorescence and linear response of Ir-diol ( $5 \mu \mathrm{M}$, pretreated with $20 \mu \mathrm{M} \mathrm{ONOO}^{-}$for 5minutes) toward different concentrations of GSH.

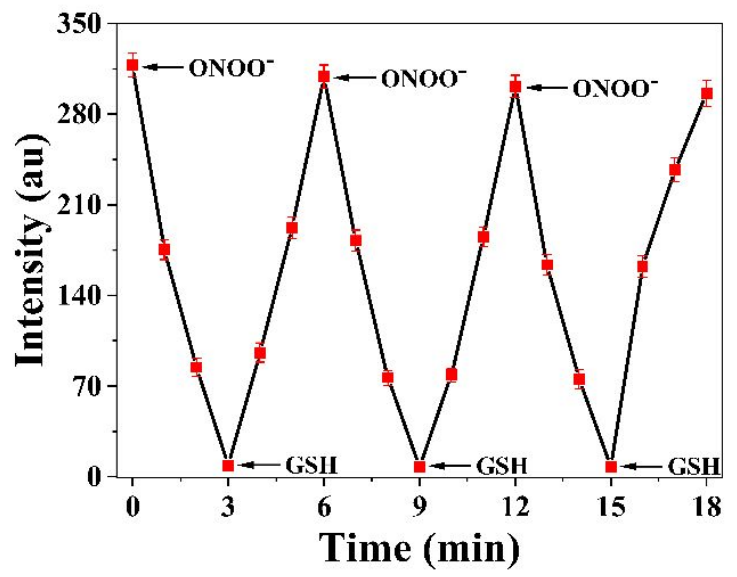

Figure S8. Plots of emission intensity response of $5 \mu \mathrm{M}$ Ir-diol to ONOO-/GSH redox cycles. $\lambda_{\text {ex }}$ $=405 \mathrm{~nm}$. Slits: $5 / 5 \mathrm{~nm}$. 


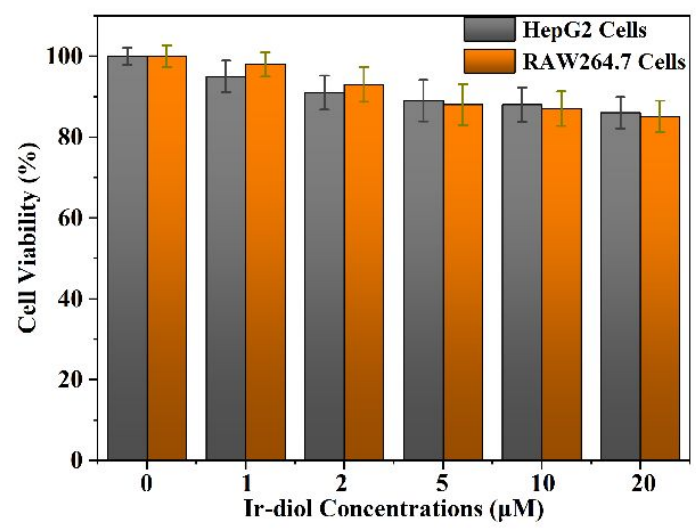

Figure S9. MTT assay of HepG2 and RAW264.7 cells with different concentrations of Ir-diol for $12 \mathrm{~h}$.

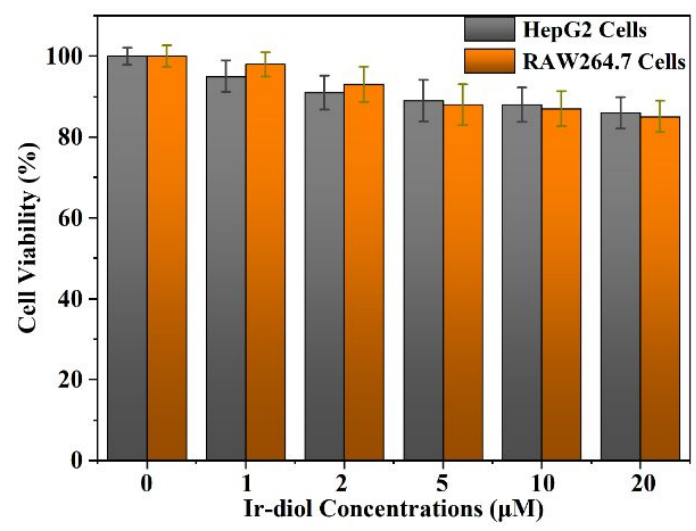

Figure S10. MTT assay of HepG2 and RAW264.7 cells with different concentrations of Ir-diol for $24 \mathrm{~h}$.

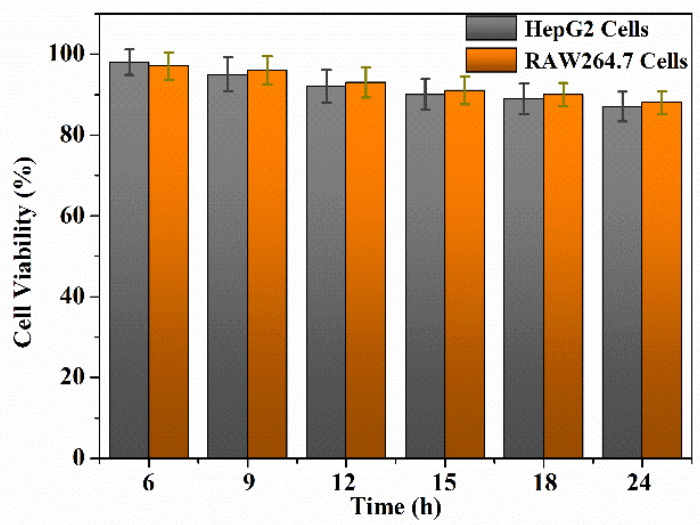

Figure S11. MTT assay of HepG2 and RAW264.7 cells with $5 \mu \mathrm{M}$ Ir-diol for different incubated time. 


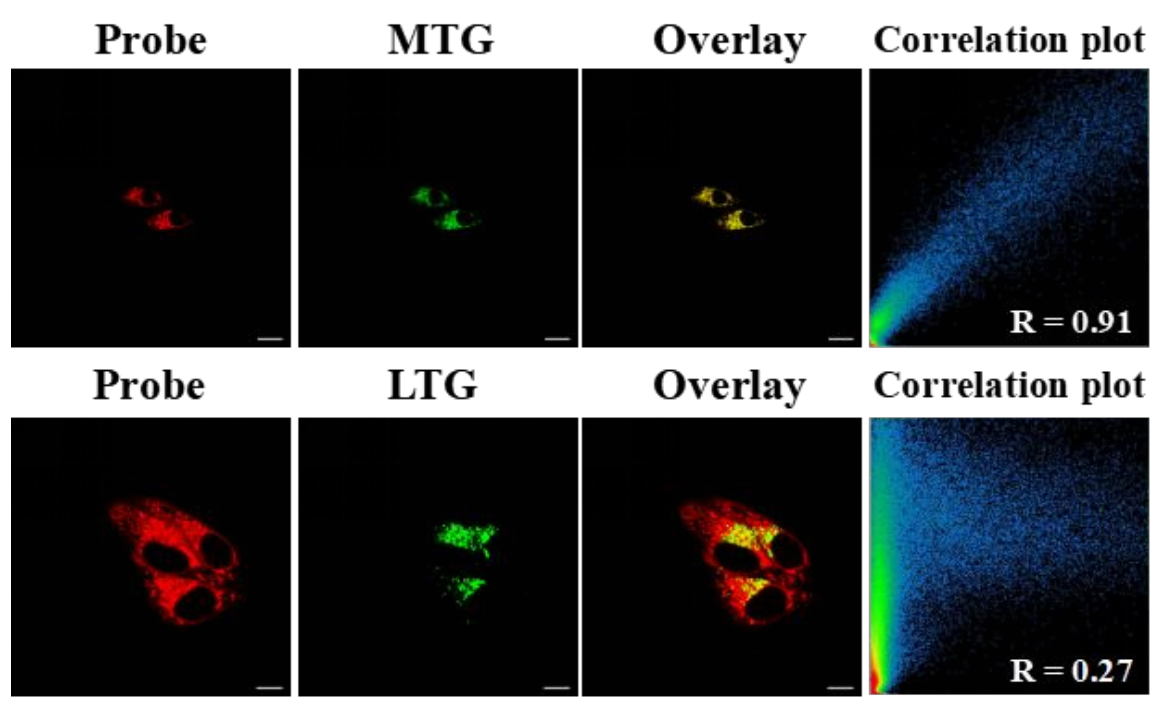

Figure S12. Images of HepG2 cells stained with Ir-diol ( $5 \mu \mathrm{M}, \lambda_{\mathrm{ex}}=405 \mathrm{~nm}$, collected: $680-720$ $\mathrm{nm}) 30 \mathrm{~min}$ and subsequently incubated with Mito-tracker Green (MTG, $100 \mathrm{nM}, \lambda_{\mathrm{ex}}=488$ nm, colleceted: 490-520 nm, Pearson's coefficient 0.91) or Lyso-tracker Green (LTG, $100 \mathrm{nM}, \lambda_{\mathrm{ex}}$ $=488 \mathrm{~nm}$, collected: $500-530 \mathrm{~nm}$, Pearson's coefficient 0.27 ) for another $40 \mathrm{~min}$.

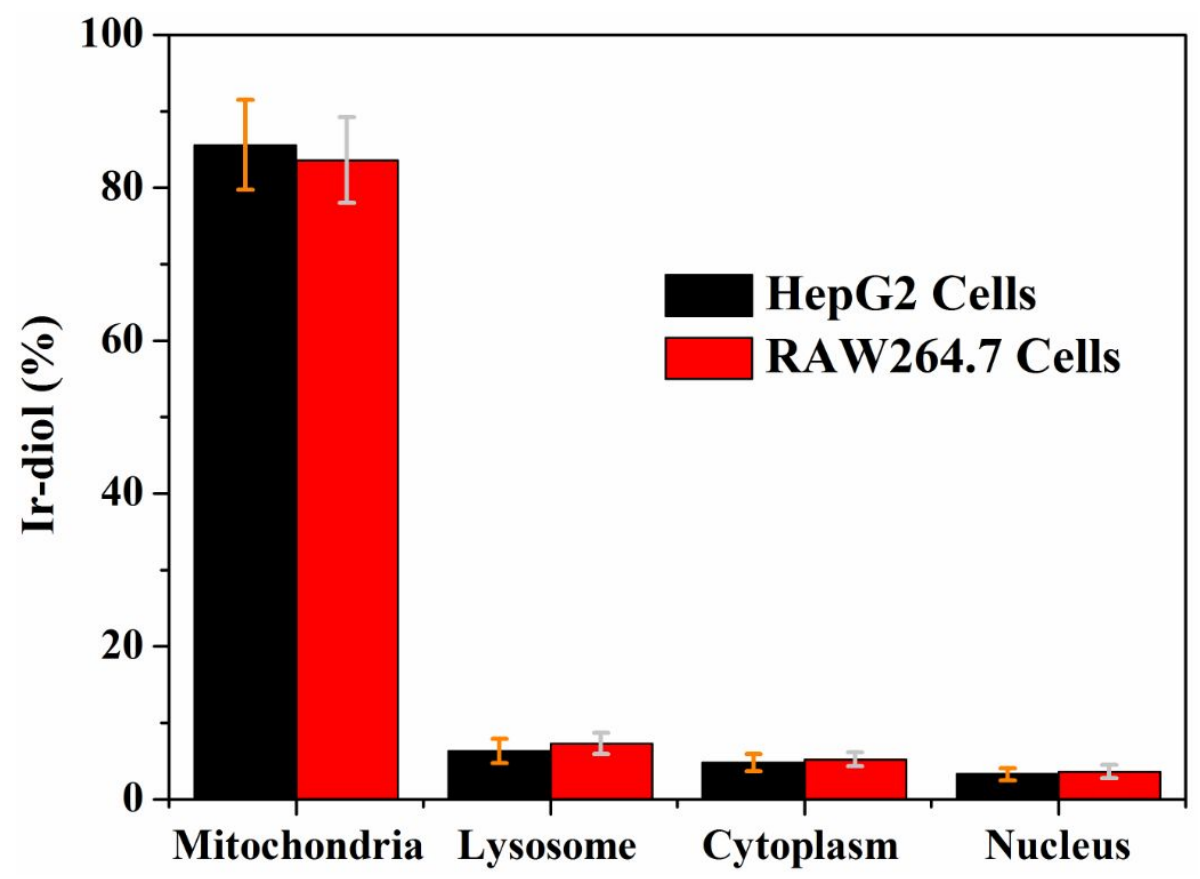

Figure S13. Percentage distribution in HepG2 and RAW264.7 cells by ICP-MS assays after treated with Ir-diol (Cytoplasm does not include Lysosome and Mitochondria in it). 